\title{
Comparison of ECMWF surface meteorology and buoy observations in the Ligurian Sea
}

\author{
R. Bozzano ${ }^{1}$, A. Siccardi ${ }^{1}$, M. E. Schiano ${ }^{2}$, M. Borghini ${ }^{2}$, and S. Castellari ${ }^{3}$ \\ ${ }^{1}$ Istituto di Studi sui Sistemi Intelligenti per l'Automazione - Sezione di Genova (CNR-ISSIA) Via de Marini 6, 16149 \\ Genova, Italy \\ ${ }^{2}$ Istituto Scienze Marine - Sezione di La Spezia (CNR-ISMAR) Forte S. Teresa, 19036 Pozzuolo di Lerici (SP), Italy \\ ${ }^{3}$ Istituto Nazionale di Geofisica e Vulcanologia (INGV) Via Creti 12, 40129 Bologna, Italy
}

Received: 27 August 2002 - Revised: 10 June 2003 - Accepted: 18 June 2003 - Published: 1 January 2004

\begin{abstract}
Since numerical weather prediction (NWP) models are usually used to force ocean circulation models, it is important to investigate their skill in reproducing surface meteorological parameters in open sea conditions. Near-surface meteorological data (air temperature, relative humidity, barometric pressure, wind speed and direction) have been acquired from several sensors deployed on an offshore large spar buoy in the Ligurian Sea (Northern Mediterranean Sea) from February to December 2000. The buoy collected 7857 valid records out of 8040 during 335 days at sea.

These observations have been compared with data from NWP models and specifically, the outputs of the ECMWF analysis in the two grid points closest to the buoy position. Hourly data acquired by the buoy have been undersampled to fit the data set of the model composed by values computed at the four synoptic hours. For each mentioned meteorological parameter an analysis has been performed by evaluating instantaneous synoptic differences, distributions, daily and annual variations and related statistics. The comparison shows that the model reproduces correctly the baric field while significant differences result for the other variables, which are more affected by local conditions. This suggests that the observed discrepancies may be due to the poor resolution of the model that probably is not sufficient to appropriately discriminate between land and ocean surfaces in a small basin such as the Ligurian Sea and to take into account local peculiarities.
\end{abstract}

The use of time- and space-averaged model data reduces the differences with respect to the in situ observations, thus making the model data usable for analysis with minor requirements about time and space resolution.

Although this comparison is strongly limited and we cannot exclude measurement errors, its results suggest a great caution in the use of the model data, especially at high frequency resolution. They may lead to incorrect estimates of atmospheric forcing into ocean circulation models, causing important errors in those areas, such as the Mediterranean

Correspondence to: R. Bozzano (boz@ge.issia.cnr.it)
Sea, where ocean circulation is strongly coupled with atmosphere and its high variability.

Key words. Oceanography; general (marginal and semiclosed seas; marine meteorology; numerical modelling)

\section{Introduction}

Surface meteorological data from numerical weather prediction (NWP) models are widely used for computing surface forcing in ocean models and climate studies. Only these products can meet the high spatial and temporal resolution at the global scale required in many applications. On the other hand, the purpose of the NWP models is to provide the best forecast, and not necessarily to closely reproduce surface fields. Thus, an evaluation of the accuracy of NWP surface data against independent measurements is necessary. However, validation tests call for high quality measurements that need to be performed in a wide variety of weather conditions. Over the sea, such data sets are rare and, consequently, few comparisons have been achieved.

In recent years, the efforts have been focused mainly on the reanalysis products and only a few studies have been devoted to the validation of the surface meteorological data provided by operational models. Weller and Anderson (1996) compared near-surface meteorology and air-sea fluxes from a buoy moored near the centre of the COARE-IFA (Coupled Ocean-Atmosphere Response Experiment - Intensive Flux Array) with European Centre for Medium Range Weather Forecast (ECMWF) analysis for the period 15 November 1992 to 15 February 1993. They found significant discrepancies between the model and the observations. Particularly, the model underestimated the wind intensity and overestimated both air temperature and specific humidity.

Weller et al. (1998) used an accurate year-long time series of surface meteorological variables collected from a surface mooring deployed off the coast of Oman during 1994-1995. They compared the observations with both climatologies and 
Table 1. Summary of meteorological sensors deployed on the ODAS Italia 1 buoy. Heights are reported in meters above the mean water line. Sensors' accuracies have been extracted from the correspondent datasheets.

\begin{tabular}{cccc}
\hline Parameter & Sensor Model & Height $[\mathrm{m}]$ & Accuracy \\
\hline Air temperature & Rotronic ag - MP102A-T4-W4W & $12.0 \mathrm{~m}$ & $\pm 0.3^{\circ} \mathrm{C}$ \\
Relative humidity & Rotronic ag - MP102A-T4-W4W & $12.0 \mathrm{~m}$ & $\pm 1.0 \%$ \\
Air pressure & Th. Friedrichs - 5006.0000 & $12.5 \mathrm{~m}$ & $\pm 1.5 \mathrm{hPa}$ \\
Wind speed & Th. Friedrichs - 4021.0000 & $13.5 \mathrm{~m}$ & $\pm 0.3 \mathrm{~m} / \mathrm{s}$ \\
Wind direction & Th. Friedrichs - 4121.0000 & $13.5 \mathrm{~m}$ & $2.0^{\circ}$ \\
\hline
\end{tabular}

concurrent data from the United States National Centers for Environmental Prediction (NCEP) reanalysis and ECMWF operational analysis. This last comparison showed that the model provided realistic surface winds, but failed to replicate other observed surface meteorology and to produce realistic heat fluxes.

These studies reveal important differences between observations and the model's predictions, which need to be considered for a possible contribution to model improvements. Operational NWP models are constantly evolving, and direct measurements are necessary for verifying and developing the models products. Fixed buoys are appealing platforms, because they can collect good quality data in a continuous way and under all weather conditions.

Validation tests of operational NWP products against direct offshore observations have never been performed over the Mediterranean Sea, although they are particularly necessary. The coupled ocean atmosphere system in this region is extremely complex, with several feedback mechanisms and very large space-time variability, that makes data analysis and numerical modelling a difficult effort.

In order to develop marine forecasting models for this basin, which require surface forcing data with high spatial and temporal resolution, the operational products of numerical atmospheric models are often used as they were measurements really acquired at sea. Thus, it becomes absolutely necessary to evaluate the skill of the operational products for the Mediterranean Sea.

A spar buoy worked in the Ligurian Sea from 1 February to 31 December 2000. The Ligurian Sea is the more inland sea of the Mediterranean. The northern part is surrounded by Alps, while it is limited by the Corsica Island to the southward direction. These orographic constraints and the thermal contrast between land and sea give rise to specific local effects that influence the general circulation of both atmosphere and ocean. Important processes in this area are the Western Mediterranean Deep Water formation occurring in the winter in the Gulf of Lyons, the Genoa cyclogenesis (i.e. a low pressure system developing south of the Alps) and local and mesoscale conditions, responsible for intense convection phenomena often leading to extreme precipitation on the coastal zone (Kelsh et al., 2001).

The buoy data are used here for a pilot comparison with operational outputs from the ECMWF. Since atmospheric model validation was not the original scope of the buoy's deployment, the available parameters for this type of analysis are air pressure, air temperature, humidity, wind speed and direction at the sea surface only.

This study is particularly devoted to the oceanographic community working on the Mediterranean Sea which often employ NWP products to compute the atmospheric forcing in ocean circulation models. In a region where validation tests have been never performed, this work should offer a qualitative view of the uncertainties due to the use of this type of data rather than direct observations.

In Sect. 2, the data sets used in the study are described. A brief description of the weather situations recorded during the year is given in Sect. 3. The comparisons are presented in Sect. 4, which is followed in Sect. 5 by a summary and a discussion of the results.

\section{Data sets}

\subsection{The ODAS Italia 1 data set}

Within the Ligurian Basin (Northern Tyrrhenian Sea), the ODAS Italia 1 buoy (Cavaleri, 1984) represents an offshore measuring location without any shield from winds and waves, because of its mooring site in $1270 \mathrm{~m}$ of deep water about $68.5 \mathrm{~km}$ far from the coast (Siccardi et al., 1996). It is a spar buoy, about $50 \mathrm{~m}$ long and 11 tons in weight, with a small laboratory on its top (Fig. 1). The buoy is a stable measuring platform, especially if compared with other types of buoys usually used for collecting meteorological and surface data in the ocean. Its design (e.g. total mass, unity buoyancy at the sea level, and damping disk) allows for negligible sensitivity to sea heave (Berteaux, 1976; Carpenter et al., 1995). The buoy is equipped by a set of meteorological and marine sensors. The characteristics of the meteorological sensors (wind speed and direction, air temperature, air pressure, relative humidity) installed on the buoy and used in this study are detailed in Table 1.

Instruments at sea include four water temperature sensors distributed from the surface down to $37 \mathrm{~m}$ in depth, two electromechanical current meters and a wave measuring system composed of three upward looking acoustic altimeters. Other sensors, such as a two-axis inclinometer, a compass, and a 


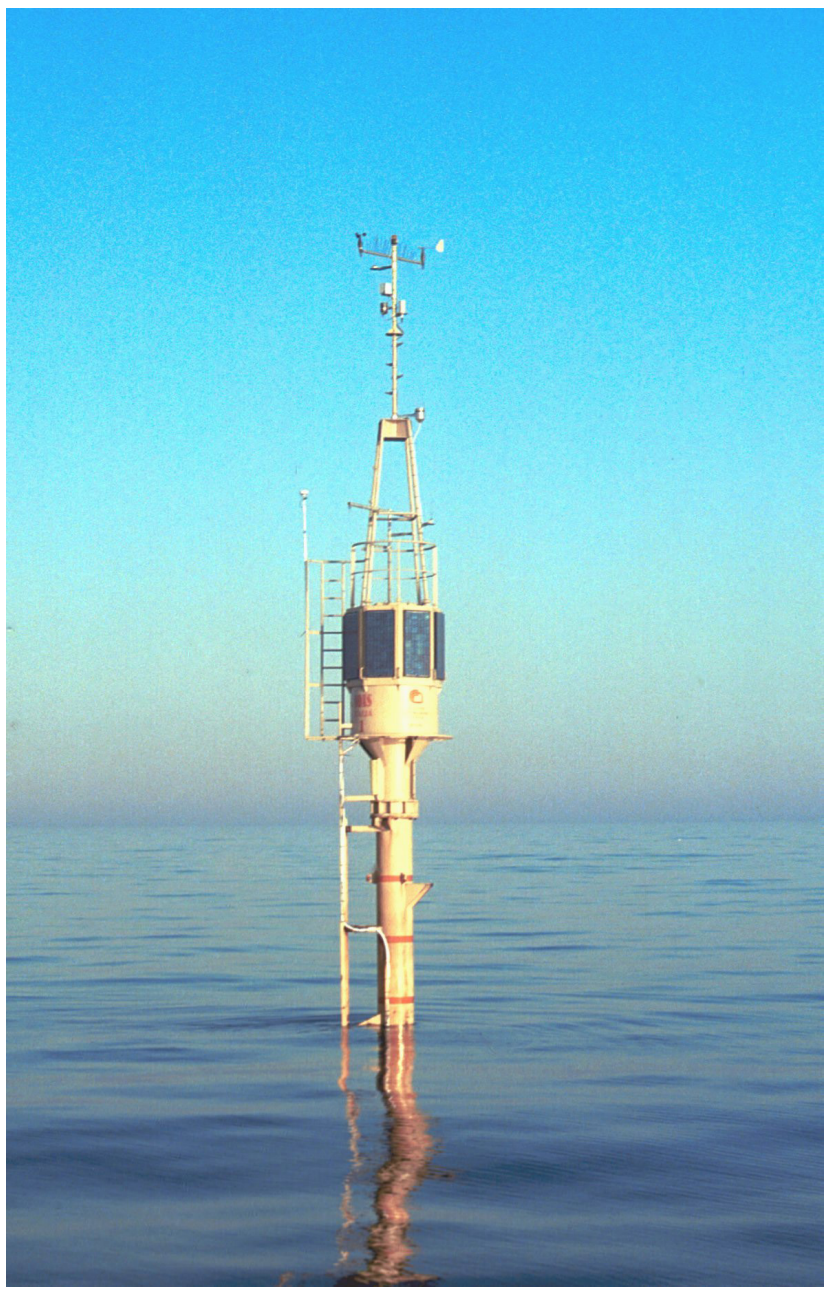

Fig. 1. Photo of the ODAS Italia 1 buoy deployed in the Ligurian Sea, showing meteorological sensors on the superstructure and the small laboratory, surrounded by the solar panels, hosting the acquisition and transmission systems.

GPS, are used to measure the trim and the position of the buoy.

Measurements are collected by an acquisition system installed in the small laboratory on the top of the buoy. Although the acquisition system can be operated with any desired sampling interval, the employed default operating mode provides a data record every hour. Acquired records are transferred in near real-time to the shore station by means of a mobile phone link.

This study is based on hourly data collected by the buoy from 1 February to 31 December 2000. Only few and short gaps of data occurred, essentially due to maintenance activities. Gaps only one hour long have been filled by means of interpolation. The remaining data gaps are listed in Table 2. The system collected 7857 valid records out of 8040 during 335 days at sea, hence achieving a success rate of about $93 \%$. Of course, the data of this platform were not assimilated by the ECMWF model.
Table 2. Summary of data gaps in the buoy data set in the period running from 1 February to 31 December 2000.

\begin{tabular}{ccc}
\hline $\begin{array}{c}\text { Start Date and Time } \\
\text { [dd/mm - hh:mm UTC] }\end{array}$ & $\begin{array}{c}\text { End Date and Time } \\
\text { [dd/mm - hh:mm UTC }]\end{array}$ & $\begin{array}{c}\text { Duration } \\
{[\mathrm{h}]}\end{array}$ \\
\hline 11/02 - 10:00 & $11 / 02-14: 00$ & 5 \\
14/03 - 11:00 & $15 / 03-13: 00$ & 27 \\
09/04 - 08:00 & $10 / 04-02: 00$ & 19 \\
11/04 - 13:00 & $13 / 04-07: 00$ & 43 \\
12/06 - 13:00 & $12 / 06-15: 00$ & 3 \\
08/09 - 22:00 & $08 / 09-23: 00$ & 2 \\
09/09 - 05:00 & $12 / 09-16: 00$ & 84 \\
\hline
\end{tabular}

\subsection{The ECMWF data set}

The buoy data were compared with the operational analysis of the ECMWF. The surface variables used in this comparison are: mean sea level pressure, 2-m air temperature, $2-\mathrm{m}$ dew point temperature and $10-\mathrm{m}$ wind components, which are routinely produced by the 6-h analyses on a regular latitude-longitude grid of size $0.5625^{\circ} \times 0.5625^{\circ}$, corresponding to $62 \mathrm{~km} \times 46 \mathrm{~km}$ at the latitude of $43^{\circ} \mathrm{N}$. Six grid points, drawing up the boundaries of the North Ligurian Sea in which the buoy is located, have been selected for the comparison (Fig. 2). During the period under examination, the model underwent some changes, the most relevant of them was an upgrade of the model resolution from 21 November (Jakob et al., 2000). A full description of the revisions during 2000 may be found on the ECMWF web site (http://www. ecmwf.int/services/data/technical/description_2000.html).

\section{Weather during year 2000}

The analysis performed by the Meteo-Hydrological Center of Liguria Region indicates that the weather conditions during the year 2000, even confirming the climate trend observed in the last years, were anomalous in comparison with the climatological mean. Particularly, the air temperature was higher than the climatological mean during the cold period, while the precipitation was characterized by intense events during relatively few rainy days.

During February and March, the precipitation was scarce due to the persistence of anticyclonic circulation. This situation was only occasionally interrupted by depression waves associated with strong north-westerly winds during which very low humidity values were recorded. The period from April to June was characterised by great instability, with the air temperature showing sudden and appreciable jumps above the seasonal mean. Due to a delay in the establishment of the Azores anticyclone, even the summer was anomalous. In July, Atlantic perturbations penetrated into the Western basin, and they reduced the temperature and increased the number of rainy and windy days. In the last months, the weather was characterised by intense perturba- 


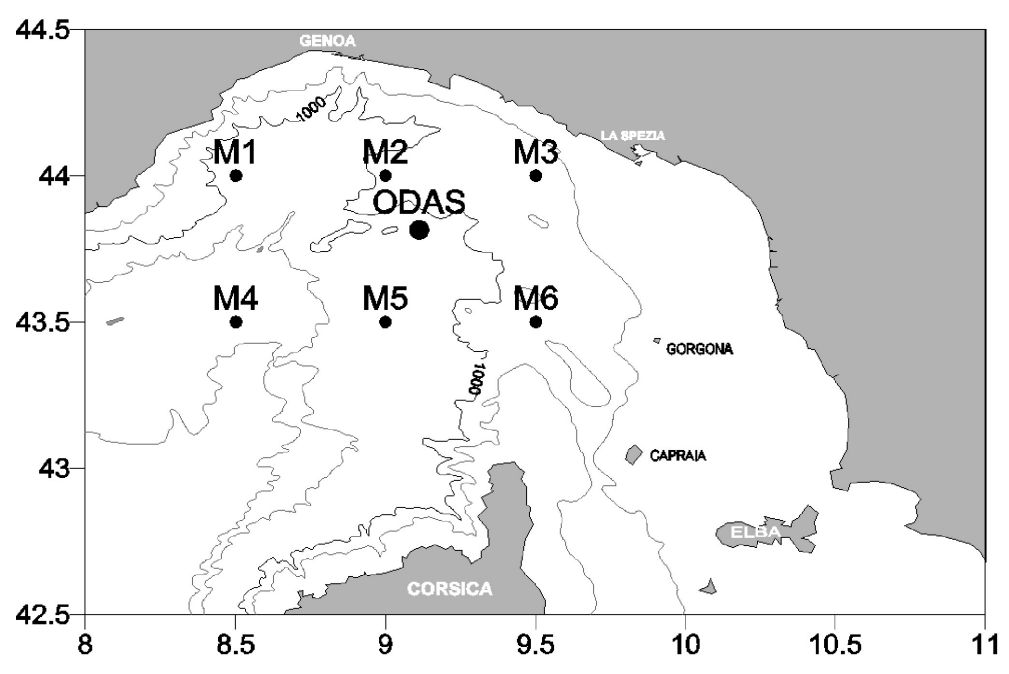

Fig. 2. Map of the Ligurian Sea, included between the Italian Riviera and Corsica Island, showing the location of the ODAS Italia 1 buoy and the ECMWF grid points used in the analysis.

tions with southern winds, which led the temperature and the precipitation to be above the climatological values. In particular, a severe flood seriously damaged the Ligurian coast on 6 November. This was produced by an extensive trough moving southward over the Mediterranean and by the contemporaneous presence of an orographic low over the Ligurian Sea. The pressure underwent a sudden decrease (more than $20 \mathrm{hPa} / 12 \mathrm{~h}$ ), while strong Sirocco winds were associated with the heavy precipitation.

Time series of the meteorological observations recorded by the ODAS Italia 1 buoy from 1 February to 31 December 2000 are plotted in Fig. 3.

\section{Comparison}

None of the ECMWF grid points overlap the buoy's position. M2, which is the grid point closest to the buoy's position, is located about $20 \mathrm{~km}$ northward in the Gulf of Genoa and may not be quite representative of the open sea conditions in which the buoy really operates. A more suitable grid point for the comparison should be M5, situated about $35 \mathrm{~km}$ southward. The use of a single no-overlapping grid point is questionable, but, on the other hand, even a linear interpolation between the values at these two ECMWF grid points may be problematic, owing to the complexity of the area and the coarseness of the model grid. Therefore, the comparison is performed with M2 and M5 grid points separately and with "average basin" values obtained by averaging the outputs of the model in the six grid points delimiting the area of the North Ligurian Sea.

Only the observations taken at the four synoptic hours have been considered, in order to compare the buoy's measurements with the ECMWF data. However, the hourly data collected by the buoy are used to investigate if the sampling at the main four synoptic hours is sufficient for reproducing the examined physical fields. The comparison has been carried out on both hourly and mean daily val- ues. The parameters examined here are: the surface atmospheric pressure, the air temperature, the dew point temperature, the wind speed and direction. The air pressure measured upon the buoy was reduced to the mean sea level using the hydrostatic equation. The air temperature and the humidity of the buoy's data were adjusted from their observed height to the ECMWF height of $2 \mathrm{~m}$, by using bulk formulae and Businnger-Dyer relationships to correct for stability (Smith, 1988). The computation scheme adopted here is given in Appendix A. It is important to note that the uncertainty in these formulations is high. For these reasons, the height adjustment has also been performed by using a different parameterisation scheme included in Version $2.6 \mathrm{~b}$ of the COARE heat fluxes program available at the web site address ftp://ftp.etl.noaa.gov/et7/anonymous/cfairall/bulkalg. However, the results were very similar to those present here.

The humidity was converted into specific humidity, adjusted to $2-\mathrm{m}$ and then the $2 \mathrm{~m}$ dew point temperature was computed. The wind speed was not adjusted to the ECMWF height, since the correction for the small height difference can be neglected thereby avoiding the introduction of the uncertainties due to the applications of the bulk algorithms.

For every mentioned parameter, the three basic statistical measures suggested by Wilks (1995), mean bias error (MBE), root mean square error (RMSE) and correlation coefficient (CC) have been calculated.

\subsection{Air pressure}

The atmospheric pressure measured upon the buoy ranges from 988 to $1037 \mathrm{hPa}$. The highest and lowest values are recorded during the winter months, while the baric field is more stable during the summer, as it typically occurs in the Mediterranean region. More than $60 \%$ of the days show a mean daily variation less than $4 \mathrm{hPa}$. The annual mean difference between the mean daily values obtained with the two different temporal resolutions (namely, $1 \mathrm{~h}$ and $6 \mathrm{~h}$ ) is about $0.01 \mathrm{hPa}$, with most of the differences $(80 \%)$ within the range 

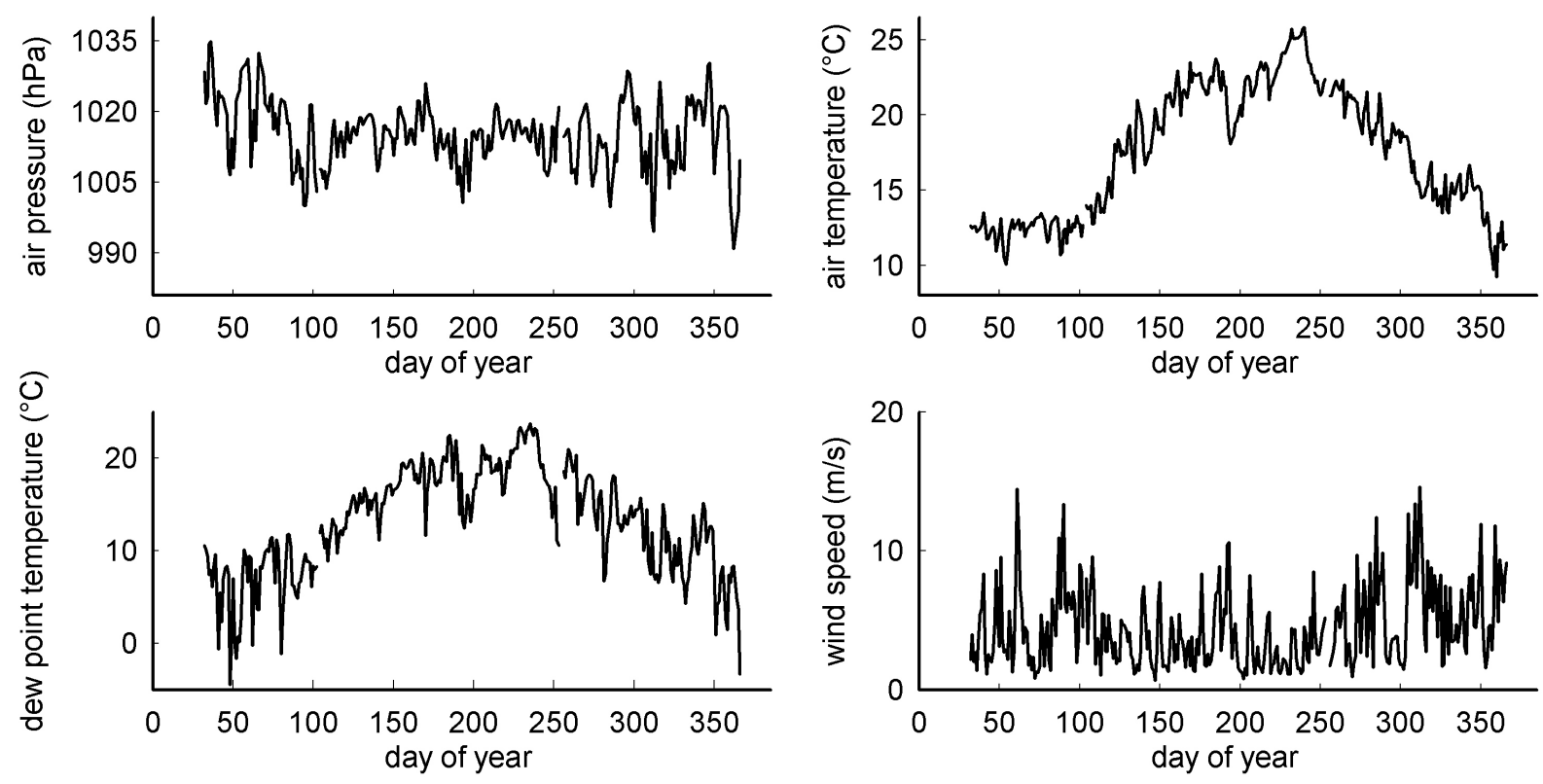

Fig. 3. Time series of near-surface meteorological observables measured at the ODAS Italia 1 buoy from 1 February to 31 December 2000. Daily averages of barometric pressure, air temperature, dew point temperature and wind speed.

Table 3. Hourly and daily statistics for the air pressure in terms of mean bias error (MBE) and root mean square error (RMSE).

\begin{tabular}{lcccccc}
\hline & \multicolumn{3}{c}{ Hourly Values } & \multicolumn{3}{c}{ Daily Values } \\
& MBE (hPa) & RMSE (hPa) & CC & MBE (hPa) & RMSE (hPa) & CC \\
\hline M2 & 0.10 & 0.73 & 0.98 & 0.09 & 0.57 & 0.99 \\
M5 & -0.05 & 0.68 & 0.98 & -0.06 & 0.53 & 0.99 \\
Basin & 0.06 & 0.67 & 0.98 & 0.05 & 0.52 & 0.99 \\
\hline
\end{tabular}

$\pm 0.5 \mathrm{hPa}$. Therefore, the sampling at the four synoptic hours is sufficient for monitoring the baric field. The comparison between the direct measurements and the model outputs (Fig. 4) gives satisfactory results.

The difference between hourly data is within $\pm 1 \mathrm{hPa}$ for more than $90 \%$ of the data. The annual RMSE is always less than $1 \mathrm{hPa}$, i.e. it is comparable with the accuracy of measured data (Table 3). The correlation coefficient is greater than 0.98 . Statistics obtained by hourly and mean daily data are very similar.

The result does not change when comparing the buoy's observations with the basin-averaged ECMWF predictions, owing to the small space variability of the model data. Even on the hourly scale, the ECMWF predictions reproduce well the baric field and its variations over the Ligurian basin. The ECMWF model captures well maxima and minima occurring over the area and predicts well the extreme event occurring on 6 November, when the pressure dropped of more than $20 \mathrm{hPa}$ in less than twelve hours (Fig. 5).

\subsection{Air temperature}

The air temperature values recorded by the buoy range between 7.0 and $27.5^{\circ} \mathrm{C}$. As it usually occurs at sea, the air temperature maximum is recorded in the afternoon, between 14:00 and 17:00 UTC, while the minima take place in the early morning, between 04:00 and 06:00 UTC. By using the 1-h temporal resolution data set, the annual mean amplitude of the daily cycle is about $2.0^{\circ} \mathrm{C}$.

About $37 \%$ of the days show a daily variation of less than $1.5^{\circ} \mathrm{C}$. The amplitude of the daily cycle is greater than $4.5^{\circ} \mathrm{C}$ for only $6 \%$ of days, most of them during spring and autumn. By using the 6-h temporal resolution, the annual mean amplitude of the daily cycle is reduced to about $1.3^{\circ} \mathrm{C}$, with more than $70 \%$ of the days showing a variation of less than $1.5^{\circ} \mathrm{C}$ and only $1.5 \%$ greater than $4.5^{\circ} \mathrm{C}$. Using the 6 -h temporal resolution, the daily maximum is underestimated by about $0.4^{\circ} \mathrm{C}$ on the annual average, while the minimum is overestimated by about the same. The differences of the mean daily values due to the different resolution are in the range $\pm 0.7^{\circ} \mathrm{C}$, with an annual mean of about $0.02^{\circ} \mathrm{C}$. For more than $74 \%$ of the days this difference is within $\pm 0.15^{\circ} \mathrm{C}$. Consequently, the sampling at the main four synoptic hours may be sufficient 

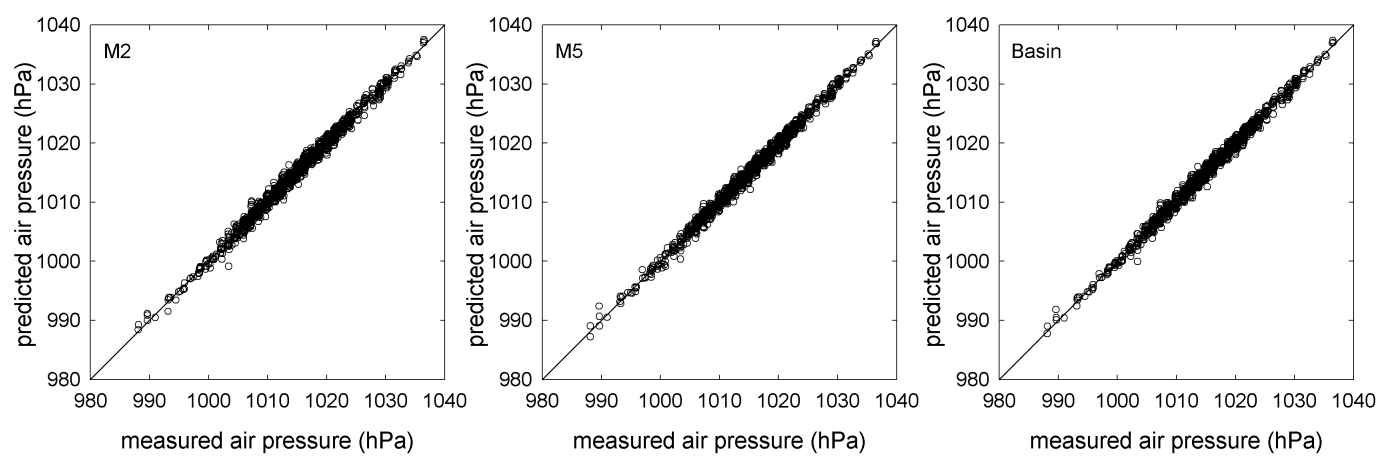

Fig. 4. Scatter plots of model vs. buoy's air pressure hourly data for the M2, M5 grid points and the "average basin".

Table 4. Hourly and daily statistics for the air temperature in terms of mean bias error (MBE) and root mean square error (RMSE).

\begin{tabular}{lcccccc}
\hline & \multicolumn{3}{c}{ Hourly Values } & \multicolumn{3}{c}{ Daily Values } \\
& $\mathrm{MBE}\left({ }^{\circ} \mathrm{C}\right)$ & $\mathrm{RMSE}\left({ }^{\circ} \mathrm{C}\right)$ & $\mathrm{CC}$ & $\mathrm{MBE}\left({ }^{\circ} \mathrm{C}\right)$ & $\operatorname{RMSE}\left({ }^{\circ} \mathrm{C}\right)$ & $\mathrm{CC}$ \\
\hline M2 & -0.11 & 1.49 & 0.95 & -0.12 & 0.89 & 0.99 \\
M5 & 0.84 & 1.61 & 0.95 & 0.82 & 1.15 & 0.99 \\
Basin & 0.04 & 1.47 & 0.95 & -0.07 & 0.83 & 0.99 \\
\hline
\end{tabular}

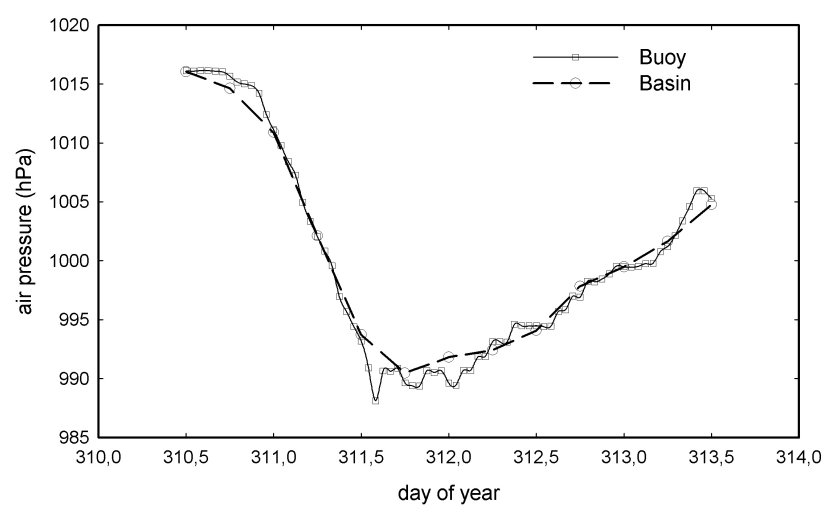

Fig. 5. Overplot of the barometric pressure drop that occurred from 5 to 9 November 2000 as measured by the buoy and predicted by the ECMWF model.

for computing the mean daily temperature, but it is not suitable for capturing the true daily cycle, particularly the daily maximum.

The comparison between the measurements and the model outputs in both M2 and M5 grid points (Fig. 6) reveals that the difference between hourly data is within $\pm 1^{\circ} \mathrm{C}$ for more than $50 \%$ of the data, with a slight increase for the southern point (M5).

The best agreement is found by using the data of the M2 grid point, with more than $87 \%$ of the differences in the range $\pm 2.0^{\circ} \mathrm{C}$ (Table 4). The air temperatures in M5 are generally higher than those of M2, due to the latitudinal temperature gradient of the ECMWF model. The annual statistics evidences a good enough consistency between measurements and predictions, and the results improve by using mean daily values instead of hourly data and by making the comparison with the basin averaged predictions. Nevertheless, these acceptable results still show some systematic mismatches.

The ECMWF model predicts a daily cycle that is substantially different from the observed one. In the model data set, the annual mean amplitude of the daily variation is about $3.0^{\circ} \mathrm{C}$, with more than $80 \%$ of the days in the range between 2.0 and $4.0^{\circ} \mathrm{C}$.

The value at 12:00 UTC is generally the highest one $(88 \%$ of cases). Most of the model values at 12:00 UTC are higher than the corresponding measurements and, especially in summer, they are often higher than the daily maxima recorded by the buoy using 24 samples/day. Thus, the ECMWF model predicts an air temperature daily cycle unusual at sea: it seems more similar to the cycle observed on the land. Since the forecast valid times may not be coincident with the times of the local daily extremes, ECMWF also provides the forecast daily maxima and minima for estimating the daily variation of the surface air temperature. However, this makes the situation worse because it implies that the predicted daily variation may still be larger than that one resulting from the analysis of the 6-h model data set.

Furthermore, during the summer, the ECMWF model usually overestimates the air temperature at all four synoptic hours, while in winter this occurs only at 12:00 UTC, being the temperatures underestimated at the other synoptic hours (Fig. 7).

The comparison performed on a monthly mean scale evidences well the seasonal distribution of the disagreement (Fig. 8). 

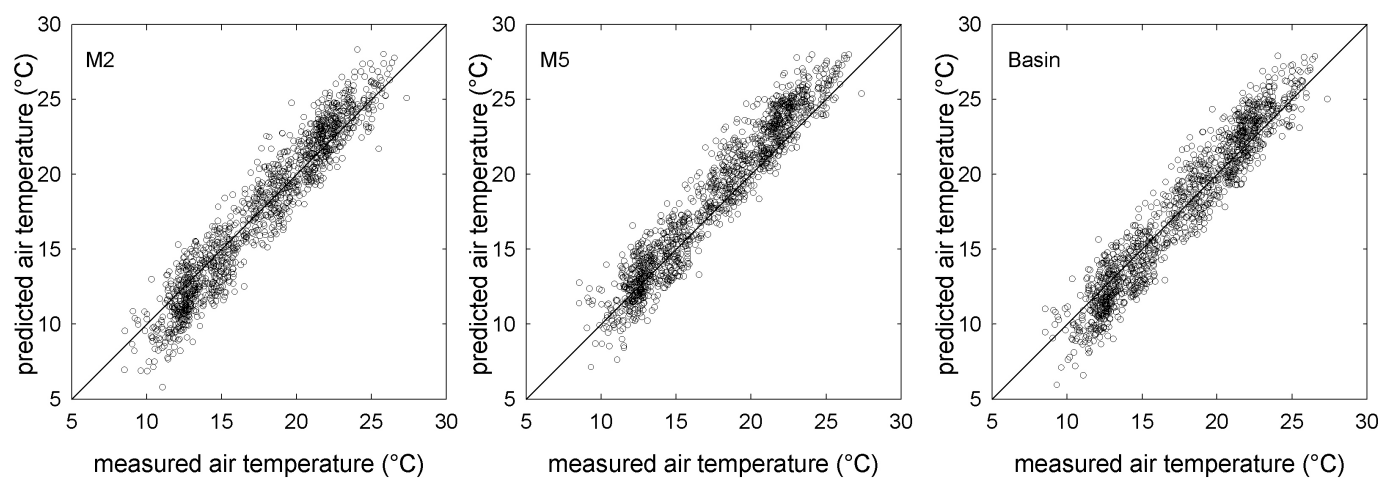

Fig. 6. Scatter plots of model vs. buoy's air temperature hourly data for the M2, M5 grid points and the "average basin".
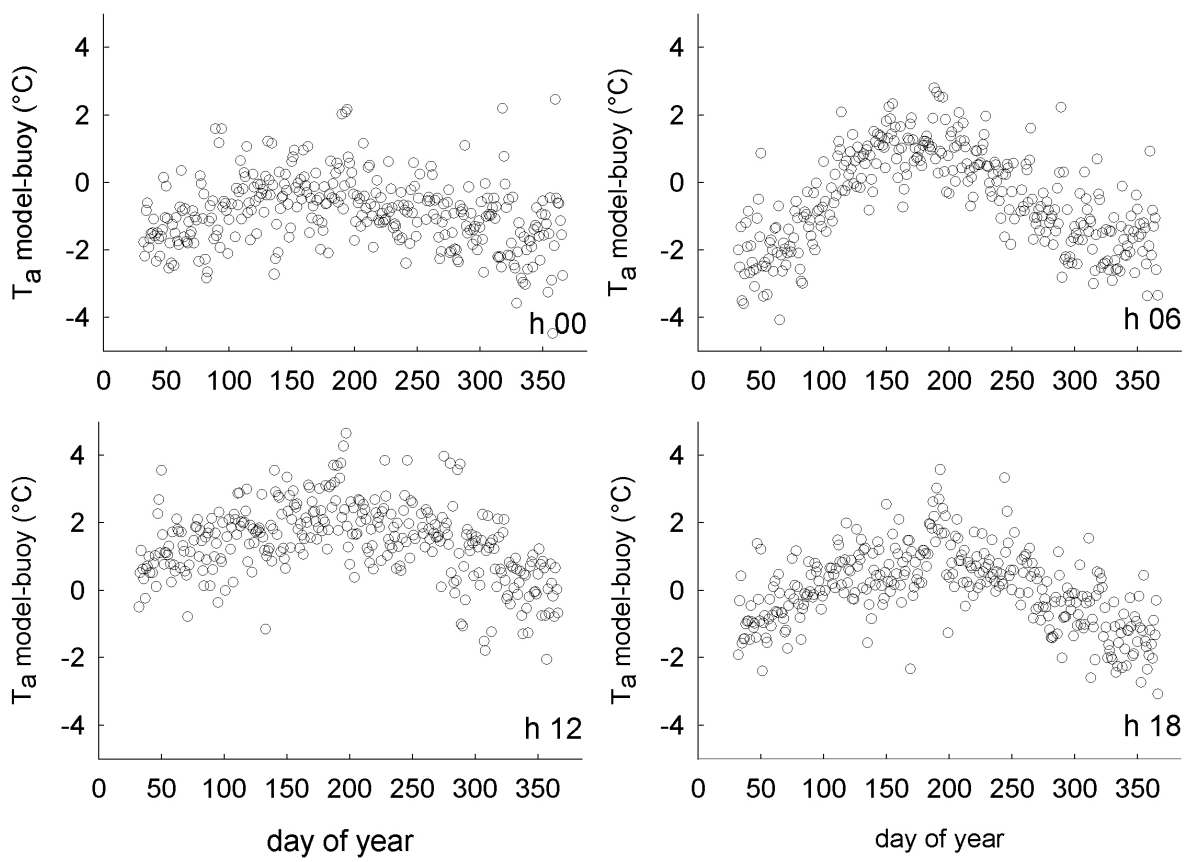

Fig. 7. Differences of hourly air temperature $\left(T_{a}\right)$ values between the model (basin average data) and the buoy as a function of the four synoptic hours.

Due to the large latitudinal thermal gradient of the predicted air temperature, the disagreement with the buoy's data is less for the values at the southern grid point during winter, and for the values at the northern grid point during summer. The variation according to longitude is not meaningful for the southern grid points. On the contrary, the air temperature predicted in the M2 grid point is always higher than the predictions in both $\mathrm{M} 1$ and $\mathrm{M} 3$ of about $1.0^{\circ} \mathrm{C}$, with these two grid points closest to the coast. However, the compensation due to the space variability of the air temperature field produced by the ECMWF model is not sufficient to hide the seasonal behaviour of the differences between predictions and measurements, as it is shown by the results of the comparison with the basin averaged predictions.

The analysis of the differences between predicted and measured air temperature with respect to other measured me- teorological parameters shows that the ECMWF model predicts air temperature values lower than the measured ones when air temperature and humidity are low and atmospheric pressure is high, i.e. in winter, under anti-cyclonic conditions (Fig. 9). On the contrary, in summer, under high temperature and humidity conditions, the ECMWF model predicts a significant warming that does not really take place.

Previous studies showed that temperature errors occur when the sensors are enclosed in radiation screens without forced aspiration (Kent et al., 1993; Anderson et al., 1998), and this is the case of the temperature sensor on board the buoy ODAS Italia 1. Nevertheless, these errors are mainly due to solar heating effects and yield an artificial increase in the temperature with the increase in the insulation. As a consequence, the disagreement between the predictions and the measurements cannot be ascribed to the shield used on the 

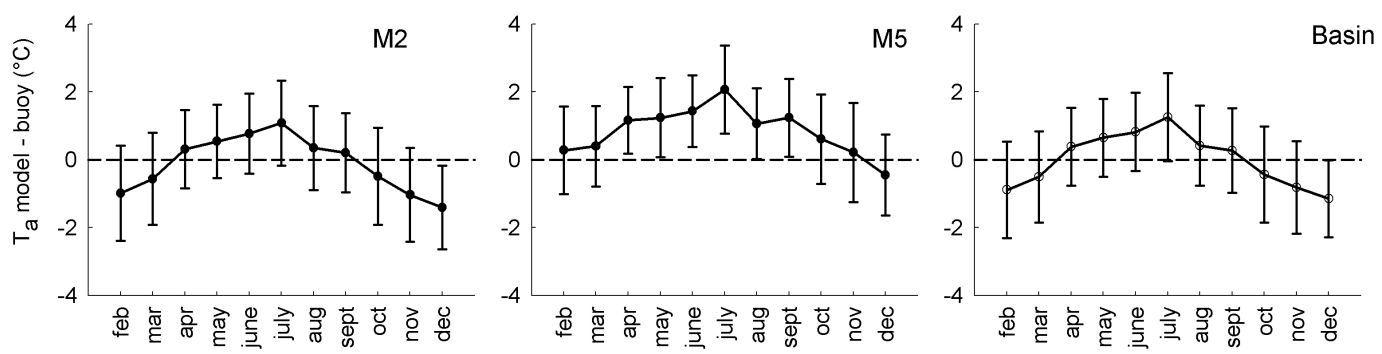

Fig. 8. Differences of monthly mean air temperature $\left(T_{a}\right)$ values between the model and the buoy in the M2, M5 grid points and for the "average basin" data.
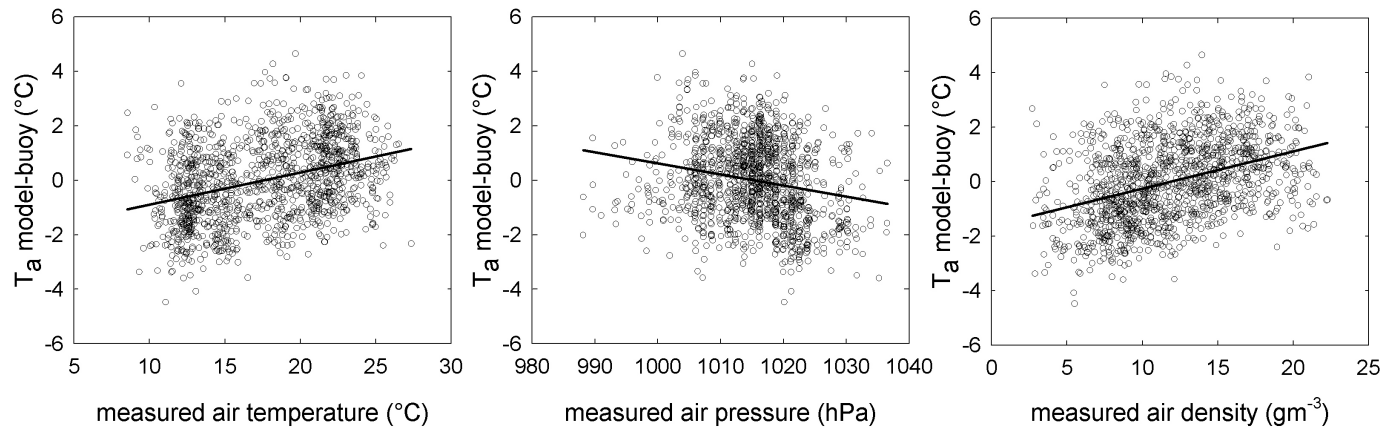

Fig. 9. Mean daily difference of air temperature $\left(T_{a}\right)$ between the basin average and the buoy's measurements with respect to some surface parameters: barometric pressure, air temperature, and water vapour density, respectively.

buoy, least of all the hourly and the seasonal distributions. In fact, the lack of forced ventilation acts in the opposite direction: it increases the measured temperature by smoothing the observed differences.

Another source of error in the measured air temperature data may be due to the height adjustment. A large variety of algorithms has been proposed to perform this adjustment. All algorithms derive from the same analysis but differ in the choice of parameters or functions, leading to different results. At the present, there is not a worldwide accepted parameterisation scheme (WGASF, 2000). Thus, the accuracy of the 2-m air temperature data obtained from the buoy may be questionable. However, the adjustment does not modify the $12-\mathrm{m}$ value and cannot justify the observed disagreements.

Particularly, the marked daily cycle along with the greater cooling in winter and the warming in summer, more than the bias, indicate that the ECMWF model does not properly reproduce the air temperature field. It seems that the model misevaluates the thermoregulator effect of the sea wich plays a fundamental role in smoothing both daily and seasonal excursions, especially for the warm Mediterranean Sea. This may be due to the computational scheme, but also to the low space resolution of the model. In fact, taking into account that the Ligurian Sea has a small extension and it is nearly encircled by land, the space resolution of the largescale ECMWF model may not be sufficient to completely discriminate between land and the sea surface in this specific region.

\subsection{Surface moisture}

The sensor on the buoy measures the relative humidity at the 12-m height, while the 2-m dew point temperature is the available moisture parameter in the ECMWF data set used in this study. In order to make the comparison, it is necessary to convert one moisture quantity into the other. However, any conversion relationship between moisture parameters implies the use of the air temperature data, and the previous comparison shows significant differences between measured and predicted air temperature values. Consequently, these discrepancies will have some impact on the comparison between moisture parameters. This is evident in Fig. 10 where by plotting the hourly difference between relative humidity obtained by using both dew point temperature and air temperature data given by the model and the corresponding value computed by using the dew point temperature of the model and the air temperature measured from the buoy. The bias and its seasonal distribution have to be ascribed exclusively to the differences between the measured and the predicted air temperature. Thus, it is better to convert the buoy measurements, in order to compare dew point temperature values rather than to use the model air temperature data for computing any other humidity parameter.

The dew point temperature values have been computed using the buoy's data interpolated at 2-m height and the following equation:

$T_{d p}=238.3 \times \ln (e / 610.78) /(17.294-\ln (e / 610.78))$, where $e$ is the water vapour tension (hPa) at the 2-m height. 


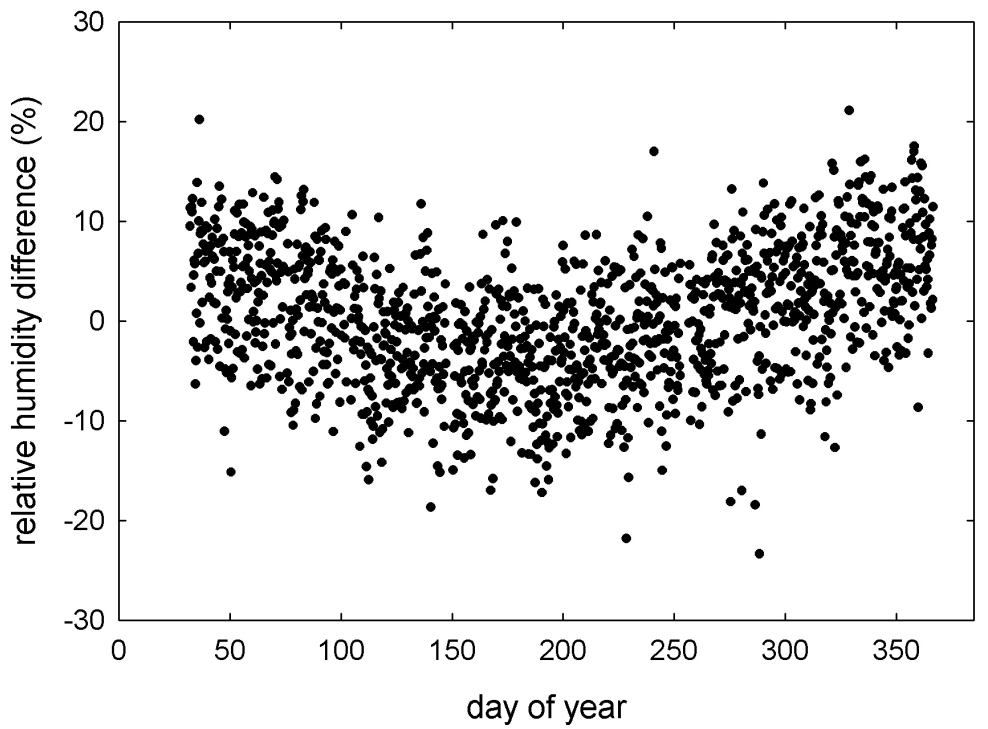

Fig. 10. Hourly differences of relative humidity due to the differences of air temperature values between the M2 grid point and the buoy.
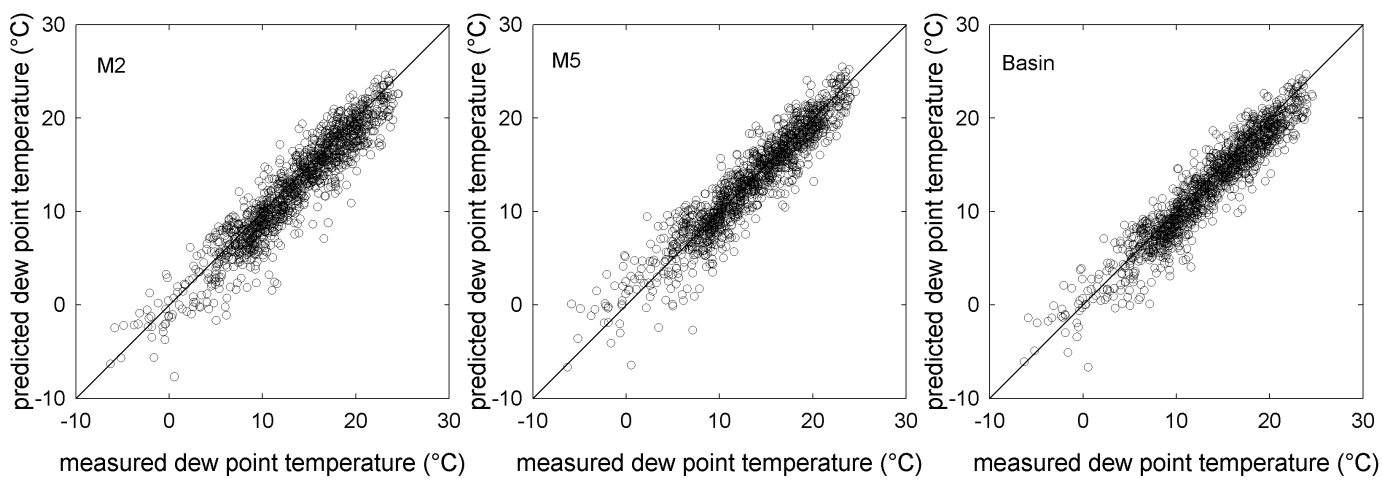

Fig. 11. Scatter plots of dew point temperature hourly data predicted by the model and measured by the buoy in the M2, M5 grid points and for the "average basin" data.

The computed values of the dew point temperature range between -6.0 and $25.0^{\circ} \mathrm{C}$. The lowest values are recorded during the winter months under strong northwestern winds. On annual average, the difference between the daily minimum and maximum is about $4.0^{\circ} \mathrm{C}$, higher in winter and lower in summer; this daily variability is very high and, although the minima are generally recorded during the night, there is not a well-defined daily cycle. The comparison between the 1-h temporal resolution data set with the data set obtained at the main four synoptic hours shows that the differences of the mean daily values due to the different temporal resolution are in the range $\pm 1.4^{\circ} \mathrm{C}$, with an annual mean of about $0.02^{\circ} \mathrm{C}$.

By using the 6-h temporal resolution, the daily variability is strongly reduced to $2.8^{\circ} \mathrm{C}$. The daily maximum is underestimated by about $0.7^{\circ} \mathrm{C}$ on annual average and for more than $47 \%$ of the days the underestimation is greater than $1.0^{\circ} \mathrm{C}$. On the other hand, the daily minimum is overestimated by about $+0.8^{\circ} \mathrm{C}$ on annual average, but about $68 \%$ of the days show an overestimation less than $0.5^{\circ} \mathrm{C}$. Thus, the sampling at the main four synoptic hours is sufficient for computing the mean daily dew point temperature, but, due to the very high daily variability of this parameter, it may not be able to capture extreme values, especially the maxima.

The predicted dew point temperatures are in the same range of the experimental values, -7.7 and $25.5^{\circ} \mathrm{C}$, and show a daily variability quantitatively similar to that one of the buoy's data but with a more defined daily cycle. The values in the southern grid points are higher than the values in northern points, in particular, the lowest dew point temperatures are correctly predicted in M1 and in M3, with the grid points closest to the coast.

The comparison between the buoy data and the model outputs in both M2 and M5 grid points (Fig. 11) reveals that the difference between hourly data is within $\pm 1^{\circ} \mathrm{C}$ for more than $57 \%$ of the data and within $\pm 2^{\circ} \mathrm{C}$ for about $80 \%$ of the data. On annual average, the small, negative MBE is counterbalanced by a very high RMSE of about $2^{\circ} \mathrm{C}$, partly ascribable 
Table 5. Hourly and daily statistics for the dew point temperature in terms of mean bias error (MBE) and root mean square error (RMSE).

\begin{tabular}{lcccccc}
\hline & \multicolumn{3}{c}{ Hourly Values } & \multicolumn{3}{c}{ Daily Values } \\
& $\operatorname{MBE}\left({ }^{\circ} \mathrm{C}\right)$ & $\operatorname{RMSE}\left({ }^{\circ} \mathrm{C}\right)$ & $\mathrm{CC}$ & $\mathrm{MBE}\left({ }^{\circ} \mathrm{C}\right)$ & $\operatorname{RMSE}\left({ }^{\circ} \mathrm{C}\right)$ & $\mathrm{CC}$ \\
\hline M2 & -0.94 & 2.18 & 0.94 & -0.95 & 1.50 & 0.98 \\
M5 & -0.25 & 1.95 & 0.94 & -0.25 & 1.17 & 0.98 \\
Basin & -0.82 & 1.95 & 0.94 & -0.82 & 1.30 & 0.98 \\
\hline
\end{tabular}

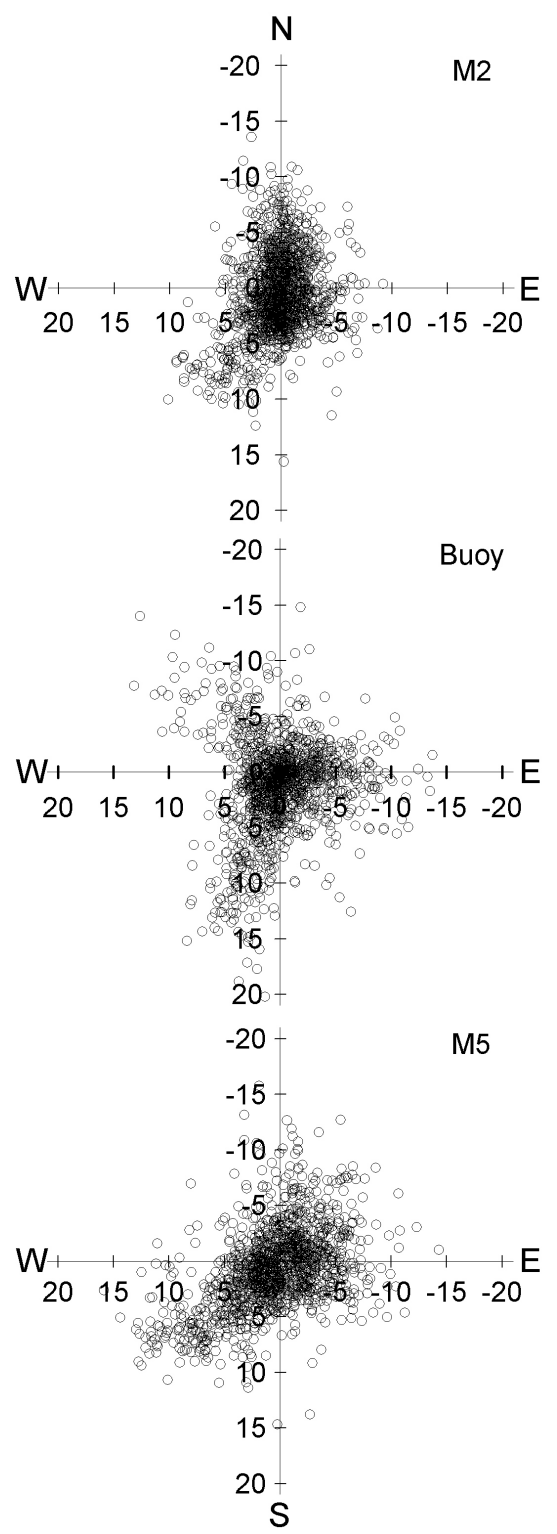

Fig. 12. Polar plots of wind data measured from the buoy and predicted by the model in the M2 and M5 grid points.

to the high variability of the dew point temperature and to the lack of a well marked daily distribution. This large spread of differences hides any possible trend, so that the disagreement does not evidence hourly or seasonal distributions, and seems to not be related to any other variable examined here. On the contrary, there is a spatial distribution of the disagreement. The northern grid points show a larger RSME, greater than $2.3^{\circ} \mathrm{C}$, and a more marked underestimation, especially in $\mathrm{M} 1$ and $\mathrm{M} 3$, which are the grid points closest to the coast $\left(-1.65\right.$ and $-1.40^{\circ} \mathrm{C}$, respectively). Thus, the spatial average on the whole area does not improve the comparison, and the results obtained by using the basin averaged predictions are very similar to those achieved for M2. The better agreement is with M5, with the grid point farthest from the coast (Table 5).

The spatial averaging is not sufficient to improve the statistics; on the contrary, averaging on time provides better results. Making the comparison by using mean daily values, the RSME is about $1.3^{\circ} \mathrm{C}$ and becomes less than $1{ }^{\circ} \mathrm{C}$ when monthly mean values are compared. The time average does not reduce the small underestimation and the spatial distribution of the disagreement, so that the best agreement between experimental data and model values is always with the predictions in M5. The analysis of the differences between daily averaged predictions and measurements does not show any dependence from the other variables and from the season, escept for the lessening of the spread.

This would suggest that there is not a systematic disagreement between model and measurements for the dew point temperature. Taking into account the high variability of the examined parameter and the accuracy of the experimental dew point temperature data, which are not directly measured from the buoy, the ECMWF model skill may be satisfactory provided that the selected grid points are far from the coast and the model data are time averaged.

\subsection{Wind}

The values measured on the buoy range from $0.01 \mathrm{~m} / \mathrm{s}$ up to $21.19 \mathrm{~m} / \mathrm{s}$, with an average value of $4.52 \mathrm{~m} / \mathrm{s}$ and a standard deviation of $3.61 \mathrm{~m} / \mathrm{s}$. About $66 \%$ of the recorded wind speeds were less than $5 \mathrm{~m} / \mathrm{s}$, and only $9 \%$ of the data was higher than $10 \mathrm{~m} / \mathrm{s}$. The winds were generally low during the first months of the year, while the highest wind speeds (higher than $17 \mathrm{~m} / \mathrm{s}$ ) were recorded during July and August. Most of the speeds higher than $8 \mathrm{~m} / \mathrm{s}$ were recorded for southsouthwest and northwest (Fig. 12).

Some moderate easterly winds were also measured. Only minor changes in the annual wind speed distribution are appreciable by considering the two temporal resolutions avail- 

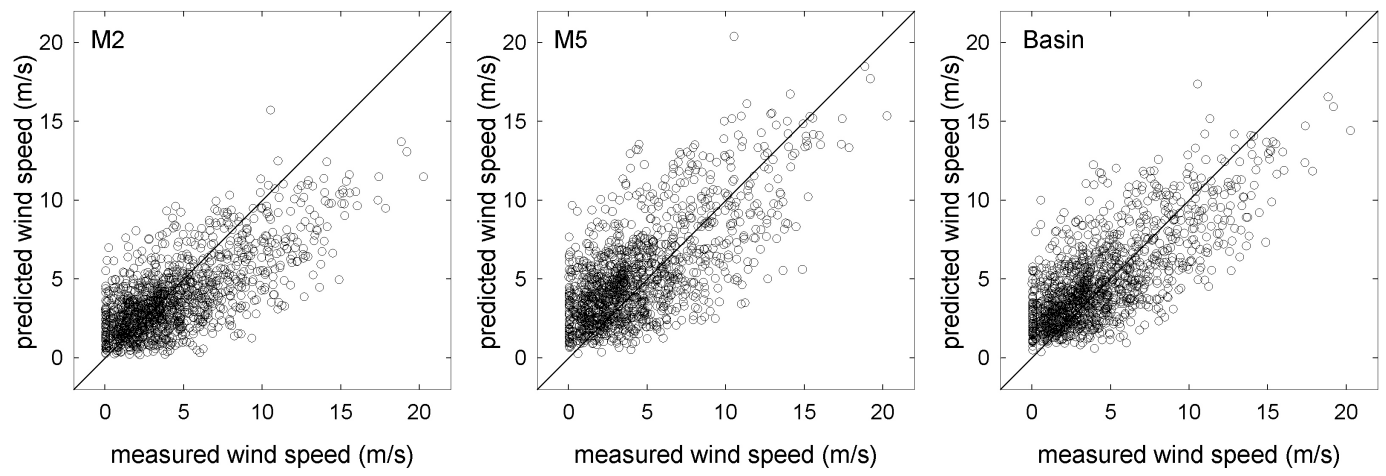

Fig. 13. Scatter plots of hourly wind data measured from the buoy and predicted by the model in the M2, M5 grid points and for the "average basin".

able from the buoy. The differences between the mean daily values computed by using the two temporal resolutions are nearly always in the range $\pm 2 \mathrm{~m} / \mathrm{s}$, increasing with the day variability.

The wind field produced by the ECMWF model is significantly different from the measured one (Fig. 12). Modelled values range from $0.13 \mathrm{~m} / \mathrm{s}$ up to $15.62 \mathrm{~m} / \mathrm{s}$, with an average value of $3.84 \mathrm{~m} / \mathrm{s}$ and a standard deviation of $2.45 \mathrm{~m} / \mathrm{s}$ for the $\mathrm{M} 2$ grid point, and from $0.22 \mathrm{~m} / \mathrm{s}$ up to $16.07 \mathrm{~m} / \mathrm{s}$ (average value of $4.68 \mathrm{~m} / \mathrm{s}$ and standard deviation of $3.06 \mathrm{~m} / \mathrm{s}$ ) for M5.

In general the wind speed computed for the northern grid points is lower and shows less variability than the wind speed at the southern points. Furthermore, the ECMWF model often introduces a clockwise rotation of the wind vector. Thus, in the northern M2 grid point, the highest speeds are obtained for southwesterly and northerly winds, while in the southern M5 grid point these occur for westerly-southwesterly and northeasterly winds.

The comparison shows that the model overestimates the calm and light winds $(<5.41 \mathrm{~m} / \mathrm{s})$ and underestimates near gale and gale winds $(>14.16 \mathrm{~m} / \mathrm{s})$ (Fig. 13). Taking into account only winds with a velocity higher than $5.4 \mathrm{~m} / \mathrm{s}$, the comparison indicates that the model underestimates the meridional component and overestimates the zonal component in both M2 and M5 grid points (Table 6).

Particularly, the moderate northwesterly winds are not predicted by the ECMWF model, the southerly-southwesterly winds are rotated westwards and their intensity is reduced. On the contrary, the model predicts moderate northerly winds for M2 and northeasterly in M5 that are not measured (Fig. 14).

Despite all of these discrepancies, the results of the annual statistic obtained for mean daily wind speed are satisfactory (Table 7). Furthermore, the discrepancies do not show hourly or seasonal distributions and are not related to any other variable examined here.
Table 6. Hourly and daily statistics for the wind speed components in terms of mean bias error (MBE) and root mean square error (RMSE).

\begin{tabular}{lccc}
\hline & MBE $(\mathrm{m} / \mathrm{s})$ & $\mathrm{RMSE}(\mathrm{m} / \mathrm{s})$ & $\mathrm{CC}$ \\
\hline Meridional M2 & -1.68 & 4.03 & 0.85 \\
Zonal M2 & 0.37 & 3.98 & 0.69 \\
Meridional M5 & -1.31 & 3.72 & 0.87 \\
Zonal M5 & 1.22 & 4.86 & 0.65 \\
\hline
\end{tabular}

\section{Discussion and conclusions}

For the first time in the Mediterranean Sea, a comparison has been performed between meteorological surface parameters measured from a fixed offshore buoy and the outputs of the ECMWF analysis. The buoy is moored in the Ligurian Sea, a peculiar site in the Mediterranean Sea characterised by specific atmospheric and marine phenomena. The data set has been collected from February to December 2000. The weather conditions during this year were anomalous compared to the climatological mean, but in agreement with the climate trend observed in this region during the last years.

The comparison is restricted to the basic surface meteorological parameters, air temperature, humidity, air pressure, wind speed and direction. The comparison has been performed by using only the measurements at the four main synoptic hours (00:00, 06:00, 12:00, 18:00 UTC). However, since the buoy records hourly data, the whole measurement data set has been used to investigate the skill of the 6-h sampling rate for monitoring the daily variability of the examined parameters. This analysis shows that, generally, the sampling at the main four synoptic hours is adequate for computing mean daily values, but is not sufficient for detecting the true variability of most quantities. Particularly, concerning the air temperature, the four synoptic hours are out of phase with the true daily cycle at sea, often leading to an underestimation of the daily maximum. However, due to the very smooth daily cycle, the computed mean daily value is only poorly affected 
Table 7. Hourly and daily statistics for the wind speed in terms of mean bias error (MBE) and root mean square error (RMSE).

\begin{tabular}{lcccccc}
\hline & \multicolumn{3}{c}{ Hourly Values } & \multicolumn{3}{c}{ Daily Values } \\
& $\mathrm{MBE}(\mathrm{m} / \mathrm{s})$ & $\mathrm{RMSE}(\mathrm{m} / \mathrm{s})$ & $\mathrm{CC}$ & $\mathrm{MBE}(\mathrm{m} / \mathrm{s})$ & $\mathrm{RMSE}(\mathrm{m} / \mathrm{s})$ & $\mathrm{CC}$ \\
\hline M2 & -0.61 & 2.57 & 0.69 & -0.60 & 1.74 & 0.82 \\
M5 & 0.85 & 2.78 & 0.67 & 0.82 & 1.92 & 0.80 \\
Basin & 0.43 & 2.46 & 0.72 & 0.44 & 1.58 & 0.84 \\
\hline
\end{tabular}
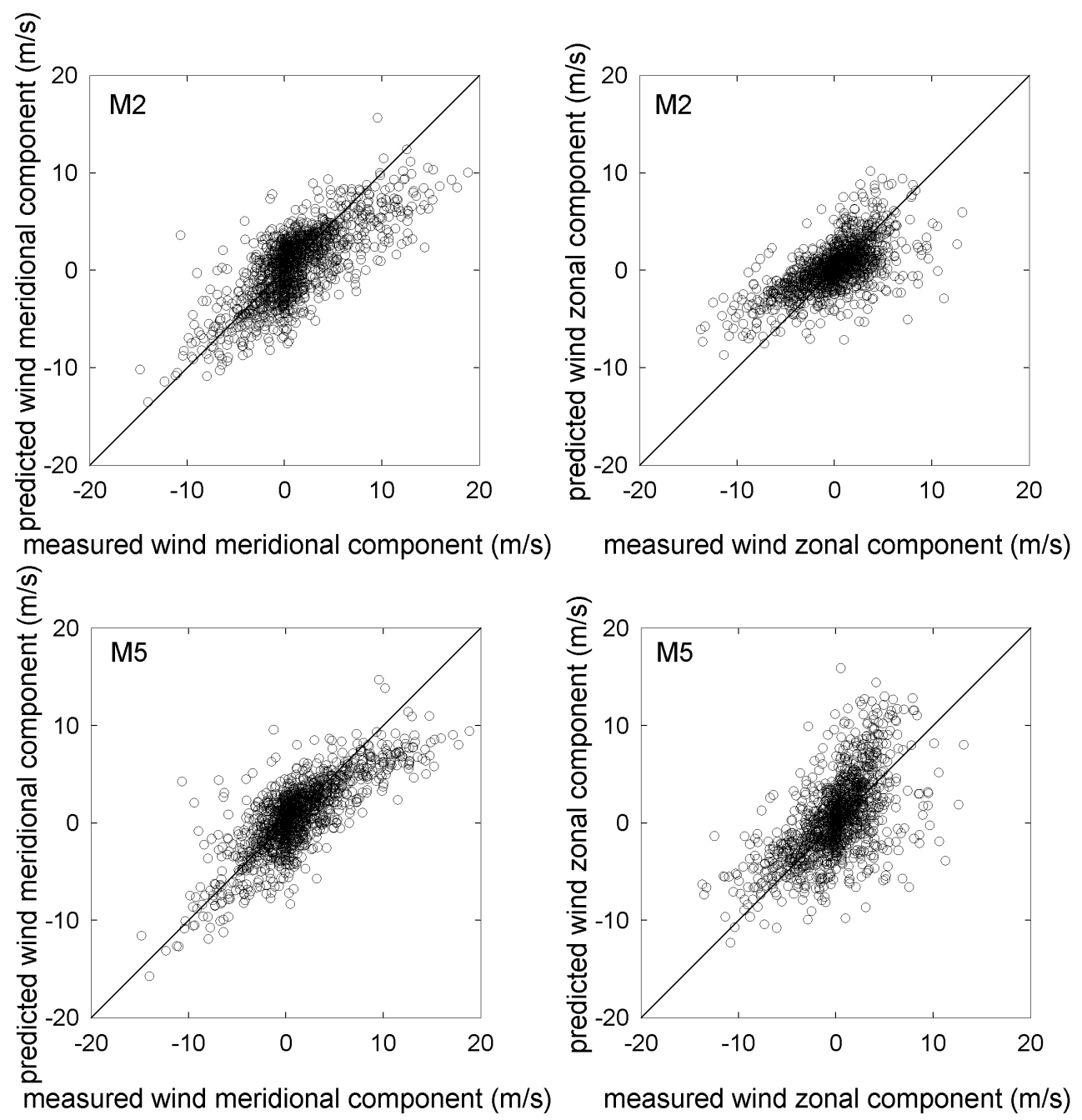

Fig. 14. Polar plots of hourly wind speed components measured from the buoy and predicted by the model in the M2 and M5 grid points.

by the lack of the extremes. In order to avoid arbitrary interpolations over a complex area, the comparison has been achieved for the two grid points closest to the buoy position and for an "average basin" obtained by averaging the outputs of the model in the six grid points delimiting the area of the North Ligurian Sea.

The comparison shows a very good agreement only between measured and predicted air pressure values, while the model skill is less for the other variables.
Mainly, the model predicts a daily variation of the surface air temperature that is not real at sea, with results higher by far than the measured one. The predicted daily cycle is more similar to those detected on land than to the cycles usually observed at sea. Furthermore, generally the model overestimates the air temperature in summer and underestimates it in winter, under anti-cyclonic conditions. Averaging on space and time improves the results, but it is not sufficient to hide the daily and seasonal behaviour of the disagreement. 
The differences between experimental and predicted dew point temperature data show a slight underestimation, and no dependence on the other physical variables examined here and on the season. On the contrary, there is a marked spatial distribution: the model skill improves when going from the northern to the southern grid points and offshore. Consequently, the use of basin averaged data does not enhance the comparison results whereas this occurs by averaging on time.

The comparison performed on the wind data shows that the model underestimates the high wind speed and overestimates the calm. The predicted wind direction is often different from the measured one, as though the wind underwent a rotation of about $30^{\circ}$ to the right of the observed winds.

These results allow us to draw some conclusions. The model has difficulty in reproducing high frequency variability. In fact, the disagreement between model and observation is greater for those variables, like wind intensity and humidity, which show a greater variability at hourly scale and it decreases averaging on time.

Furthermore, the low space resolution may not be suitable for permitting a good enough discrimination between land and sea surface in the small area of the Ligurian Sea, although the land mask of the ECMWF's model defines the selected points used in this comparison as grid points at sea. The daily cycle of the predicted air temperature, as well as the outcomes of the dew point temperature comparison, support this supposition. The low space resolution of the model may explain the results of the wind direction comparison as well.

However, it cannot be excluded that the observed disagreements depend on a inadequate parameterization of some specific characteristics of the Mediterranean Sea. Particularly, some results suggest a potential misevaluation of the thermoregulator role of the ocean, especially during the winter, when the warm sea surface helps to make the temperature of the overlying atmosphere higher. The underestimation of the near gale and gale winds and the overestimation of the calm conditions may be ascribed to a misevaluation of the orographic constraints for this specific area, but it may also be due to a short weighing of the extreme events over the basin.

Due to the lack of direct observations, in most applications, especially oceanographic models, the surface meteorological parameters obtained by the ECMWF analysis are often used, as they are data really measured at sea. The present comparison reveals some misevaluations of these predictions, especially for the high frequency data. These may lead to erroneous estimates of the atmospheric forcing in ocean circulation models and may be a serious problem for the Mediterranean Sea, where the ocean circulation is strongly related on the atmosphere and to its variability to the high frequency scales. The discrepancies are reduced using time-and-space-averaged data, suggesting that the model data may be used for studies where the interest for a continuous long time data set counterbalances the lower level of accuracy. The 6-h values have to be used with very great at- tention, since the apparent gain due to the higher temporal resolution is often annulled by the higher bias.

The true accuracy of measurements acquired over a long time from a remote platform in the open sea may be difficult to assess, even if data quality checks are routinely made. Moreover, the comparison between large-scale model outputs and measurements taken in a single specific point may be questionable. In addition, some results of this validation test may be due to specific characteristics of the Ligurian Sea. Above all, the presented results concern the model version used during 2000. In spite of this, the present comparison is particularly useful for evidencing some mismatches and it imposes further investigations on the available atmospheric data sets to be used for studies over Mediterranean Sea.

Acknowledgements. This work was partially funded by the Ministero dell'Istruzione, dell'Università della Ricerca (MIUR) within the framework of the ENEA-MIUR joint programme "Mediterranean Environment" under the contract 3.3.2.4 "Validation of geophysical parameters". The authors highly appreciated helpful comments and discussions by Stefania Sparnocchia of Istituto Scienze Marine - Sezione di Trieste (CNR-ISMAR).

Topical Editor N. Pinardi thanks two referees for their help in evaluating this paper.

\section{Appendix A Procedures for height adjustement}

The air temperature and the humidity of the buoy's data were adjusted from their observed heights $(z)$ to the ECMWF height of $2 \mathrm{~m}\left(z_{R}\right)$ by using the following equations:

$T_{R}=T_{S}+T^{*} \kappa^{-1} \cdot\left[\ln \left(z_{R} / z_{o t}\right)-\Psi_{t}\right]$
$Q_{R}=Q_{s}+Q^{*} \kappa^{-1} \cdot\left[\ln \left(z_{R} / z_{o q}\right)-\Psi_{q}\right](2)$,

where $T$ is the potential temperature $(K)$ and $Q$ is the specific humidity (KgKg-1). The subscripts " $R$ " and " $s$ " refer to the ECMWF height and to the surface, respectively. Here, $T_{s}$ is the sea surface temperature measured from the buoy at $10 \mathrm{~cm}$ depth, and $Q_{s}$ is the saturated specific humidity over saline seawater $Q_{s}=0.98 Q_{s a t}\left(T_{s}\right) . \kappa$ is the von Karman constant $(=0.4) . T^{*}$ and $Q^{*}$ are the scaling parameters for temperature and humidity, respectively. The terms $\Psi_{t}$ and $\Psi_{q}$ are the stability functions, whereas $z_{o t}$ and $z_{o q}$ are the roughness length.

Equations (1) and (2) are solved by using an iterative method based on bulk algorithms.

The roughness length for temperature and humidity are given as (Smith, 1988):

$z_{o t}=z_{o q}=z \exp \left[\kappa^{2} /\left(1.15 \cdot 10^{-3}\right) \cdot \ln \left(z / z_{o}\right)\right]$,

where $z_{o}$ is the roughness length for wind defined as (Smith, 1988):

$z_{o}=\alpha \cdot U^{* 2} / g+0.11 \cdot v / U^{*}$,

where $\alpha$ is the Charnock constant $(=0.011), v$ is the dynamic viscosity of air $\left(=14 \times 10^{-6} \mathrm{~ms}^{-1}\right), g$ is the accelaration due to gravity $\left(=9.8 \mathrm{~ms}^{-2}\right)$ and $U^{*}$ is the friction velocity. 
To inizialize the calculations, an estimated value of $z_{0}=$ $10^{-4}$ is assumed. Using this value and $z_{o t}$ and $z_{o q}$ as defined in Eq. (3), the friction velocity $U^{*}$ and the scaling parameters for temperaure and humidity are estimated with the help of the following equations:

$$
\begin{aligned}
U^{*} & =\kappa \cdot\left(U-U_{s}\right) /\left[\left(\ln \left(z / z_{o}\right)-\Psi_{m}\right]\right. \\
T^{*} & =\kappa \cdot\left(T-T_{s}\right) /\left[\ln \left(z / z_{o t}\right)-\Psi_{t}\right] \\
Q^{*} & =\kappa \cdot\left(Q-Q_{s}\right) /\left[\ln \left(z / z_{o q}\right)-\Psi_{q}\right] .
\end{aligned}
$$

For the first iteration, the stability functions $\Psi_{m}, \Psi_{t}$ and $\Psi_{q}$ are assumed to be zero, and the wind speed at the sea surface $\left(U_{s}\right)$ is taken as zero, while $U$ is the measured wind speed $(W)$ to which $W g$ is added as a gustiness factor (Fairall et al., 1996):

$U=W+W g(W g=0.5)$.

In the present computation the following equations (Smith, 1988) are used for computing the stability functions.

For stable stratification (Dyer, 1974):

$\Psi_{m}=\Psi_{t}=\Psi_{q}=-5 \cdot(z / L)$

For unstable stratification (Paulson, 1970):

$$
\begin{aligned}
\Psi_{m} & =2 \cdot \ln [(1+x) / 2] \\
& +\ln \left[\left(1+x^{2}\right) / 2\right]-2 \cdot \tan ^{-1}(x)+\pi / 2 \\
\Psi_{t} & =\Psi_{q}=2 \cdot \ln \left[\left(1+x^{2}\right) / 2\right],
\end{aligned}
$$

where

$x=[1-16 \cdot(z / L)]^{1 / 4}$.

In the above equations $L$ is the Monin-Obukhov stability length and has been defined as

$$
\begin{aligned}
& L=T \cdot U^{* 2} \cdot(1+0.61 \cdot Q) / \\
& \quad\left[g \cdot \kappa \cdot\left(T^{*} \cdot(1+0.61 \cdot Q)+0.61 \cdot T \cdot Q^{*}\right)\right] .
\end{aligned}
$$

The ratio $z / L$ is the stability parameter, and its value is positive in stable stratification and negative in unstable stratification. In near neutral stability conditions, the stability functions vanish.

\section{References}

Anderson, S. P. and Baumgartner, M. F.: Radiative heating errors in naturally ventilated air temperature measurements made from buoys, J. Atmos. Oceanic. Technol., 15, 157-173, 1998.

Bertaux, H. O.: Buoy Engineering, John Wiley \& Sons, 1976.

Cavaleri, L.: The CNR meteo-oceanographic spar buoy, Deep-Sea Research, 31, 427-437, 1984.

Carpenter, E. B., Leonard, J. W., and Yim, S. C. S.: Experimental and numerical investigations of tethered spar and sphere buoys in irregular waves, Ocean Engineering, 22 (8), 765-784, 1995.

Dyer, A. J.: A review of flux profile relationships, Bound.-Layer Meteor., 7, 363-372, 1974.

Fairall, C. W., Bradley, E. F., Rogers, D. P., Edson, J. B., and Young, G. S.: Bulk parameterization of air-sea fluxes for Tropical Ocean-Global Atmosphere Coupled-Ocean Atmosphere Response Experiment, J. Geophys. Res., 101, C12, 3747-3764, 1996.

Kelsh, M., Caporali, E., and Lanza, L. G.: Hydrometeorology of flash floods, in: Coping with Flash Floods, NATO Science Series, edited by Gruntfest, E. and Handmer, J., Kluwer Academic Pub., The Netherlands, 19-35, 2001.

Kent, E. C., Tiddy, R. J., and Taylor, P. K.: Correction of marine temperature observations for solar radiation effects, J. Atmos. Oceanic. Technol., 10, 900-906, 1993.

Jakob, C., Anderson, E., Belijaars, A., Buizza, R., Fisher, M., Gerard, E., Ghelli, A, Janssen, P., Kelly, G., McNally, A. P., Miller, M., Simmons, A., Teixeira, J., and Viterbo, P.: The IFS cycle CY21r4 made operational in October 1999, ECMWF Newsletter, no. 87, Spring 2000.

Paulson, C. A.: The mathematical representation of wind speed and temperature profiles in the unstable atmospheric surface layer, J. App. Meteor., 9, 857-861, 1970.

Siccardi, A., Bono, R., Grosso, F., Amore, R., Mantovani, R., and Mistrangelo, A.: Open sea monitoring: ODAS Italia 1, an operational system and a challenge for the future, Oceanology International 96, Brighton, UK, March 1996.

Smith, S. D.: Coefficients for sea surface wind stress, heat flux, and wind profiles as a function of wind speed and temperature, J. Geophys. Res., 93, C12, 15 467-15 472, 1988.

WGASF: Intercomparison and validation of ocean-atmosphere energy flux fields. Final Report of the Joint WCRP/SCOR working Group on Air-Sea Fluxes, WCRP-112, WMO/TD-No 1035, Geneva, Switzerland, 2000.

Weller, R. A. and Anderson, S. P.: Surface Meteorology and AirSea Fluxes in the Western Equatorial Pacific Warm Pool during TOGA Coupled Ocean-Atmosphere Response Experiment, J. Climate, vol. 9, 1996.

Weller, R. A., Baumgartner, M. F., Josey, S. A., Fisher, A. S., and Kindle, J. C.: Atmospheric forcing in the Arabian Sea during 1994-1995: observations and comparisons with climatology and models, Deep-Sea Research II 45, 1998.

Wilks, D. S.: Statistical Methods in the Atmospheric Sciences: An Introduction. Academic Press, San Diego, California, 1995. 